\title{
Guidelines and recommendations for antimicrobial minimum inhibitory concentration (MIC) testing against veterinary mycoplasma species
}

\author{
Peter C.T. HANNAN \\ Mycoplasma Experience Ltd, 1 Norbury Road, Reigate, Surrey, RH2 9BY, UK
}

(Received 10 September 1999; accepted 25 February 2000)

\begin{abstract}
The absence of standardised procedures for minimum inhibitory concentration (MIC) testing of antimicrobial agents against veterinary mycoplasma and ureaplasma species (Mollicutes) has made it difficult to compare results originating from different laboratories. This report, prepared on behalf of the International Research Programme on Comparative Mycoplasmology (IRPCM), offers guidelines and recommendations for veterinary MIC testing of these organisms in an effort to rectify this problem. The subjects discussed include suitable media for broth and agar MIC assays, storage and preparation of antimicrobial agents, standardisation of mycoplasma inocula for MIC tests, validation of equipment, incubation conditions, and determination of MIC end points. A standard medium for all veterinary mycoplasma MIC tests cannot currently be recommended, owing to the diversity of nutritional requirements of different mycoplasma species. Instead mycoplasma broths or agars giving optimal growth of specific mycoplasmas or ureaplasmas are recommended, as suboptimal growth may lead to falsely low MIC results. The importance of using standardised mycoplasma inocula, for assays using either solid or liquid media is stressed. The growth phase may be less important as lag phase and logarithmic phase cultures of Mycoplasma gallisepticum, M. synoviae, M. bovis and M. hyopneumoniae have given very similar results in liquid MIC assays. The liquid method of Tanner and $\mathrm{Wu}$ and the agar method described by Hannan et al. are compared and described in detail. Methods for calculating $\mathrm{MIC}_{50} \mathrm{~s}$ and $\mathrm{MIC}_{90} \mathrm{~s}$ are described and the interpretation of results discussed. Methods for assessing mycoplasmacidal (MMC) activity of antimicrobial agents are also described. Adoption of these guidelines should lead to more consistent MIC results being obtained between laboratories.
\end{abstract}

MIC / mycoplasmacidal / antibiotic / mycoplasma / ureaplasma

Résumé - Instructions et recommandations pour les tests de concentration minimum inhibitrice (CMI) d'antimicrobiens contre les mycoplasmes en médecine vétérinaire. L'absence de procédures standardisées pour le test de concentration minimum inhibitrice (CMI) d'agents antimicrobiens contre les mycoplasmes et uréaplasmes (Mollicutes) présents chez les animaux, rend difficile la comparaison des résultats provenant de différents laboratoires. Ce document, préparé pour le 
Programme International de Recherche sur la Mycoplasmologie Comparative (IRPCM), offre des instructions et des recommandations pour les tests d'intérêt vétérinaire de CMI de ces organismes, afin de résoudre ce problème. Les milieux appropriés pour les tests de CMI en milieu liquide et sur gel d'agar, le stockage et la préparation des agents antimicrobiens, la standardisation des inoculums pour les tests, la validation des équipements, les conditions d'incubation, et la détermination des valeurs critiques de CMI, sont les sujets abordés dans ce document. Un milieu standard pour le test de CMI de tous les mycoplasmes d'intérêt vétérinaire ne peut pour le moment pas être recommandé, à cause de la diversité des besoins nutritionnels des différentes espèces de mycoplasmes. Au contraire, des milieux liquides ou sur gel d'agar permettant d'obtenir une croissance optimale spécifique des différentes espèces de mycoplasmes et d'uréaplasmes sont recommandés, une croissance sub-optimale pouvant donner lieu à des résultats de CMI faussement basses. L'importance de l'utilisation d'inoculums standardisés de mycoplasmes dans des tests en milieu liquide ou solide, est soulignée. La phase de croissance peut être moins importante, les phases de latence et de croissance exponentielle des cultures Mycoplasma gallisepticum, M. synoviae, M. bovis et $M$. hyopneumoniae ayant donné des résultats très similaires lors de test CMI en milieu liquide. La méthode en milieu liquide de Tanner et $\mathrm{Wu}$, et la méthode sur agar décrite par Hannan et al. sont comparées et décrites en détail. Des méthodes pour le calcul des $\mathrm{CMI}_{50}$ et $\mathrm{CMI}_{90}$ sont décrites, et l'interprétation des résultats est discutée. Des méthodes pour évaluer l'activité mycoplasmacidale des agents antimicrobiens sont aussi décrites. L'adoption de ces instructions devrait permettre d'obtenir des résultats de CMI plus cohérents entre différents laboratoires.

CMI / mycoplasmacidal / antibiotique / mycoplasme / uréaplasme

\section{Table of contents}

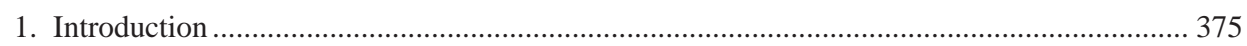

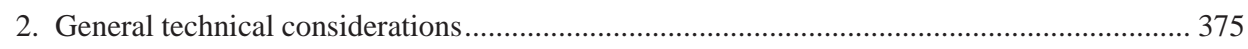

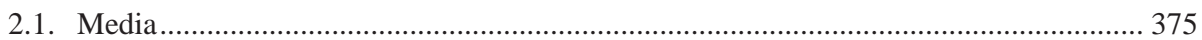

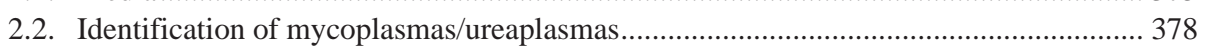

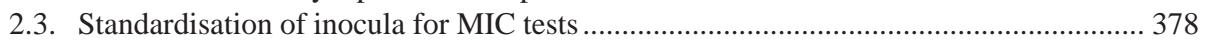

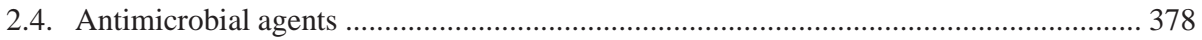

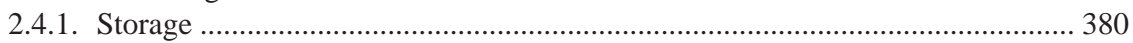

2.4.2. Preparation of antimicrobial solutions for MIC testing..................................... 382

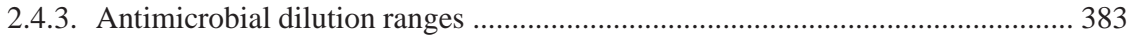

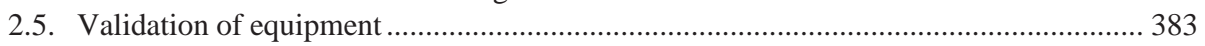

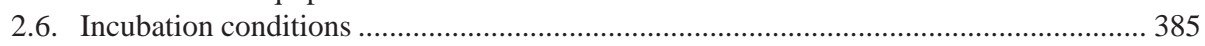

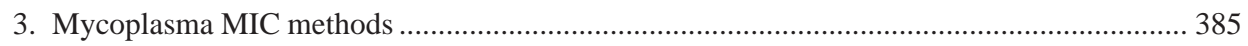

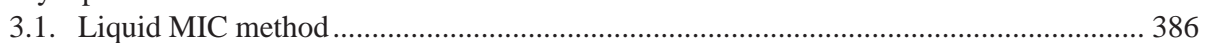

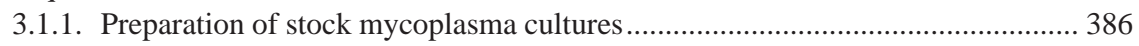

3.1.2. Preparation of mycoplasma inocula for MIC testing ........................................ 386

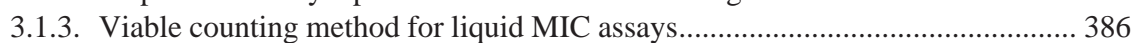

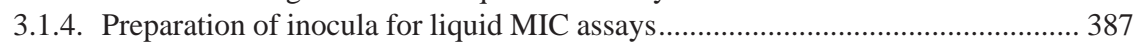

3.1.5. Modified MIC assay method of Tanner and Wu method [39] ........................... 387

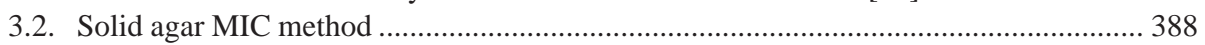

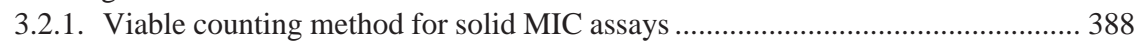

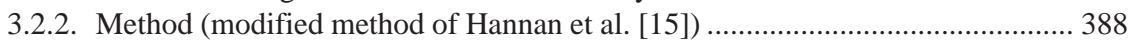

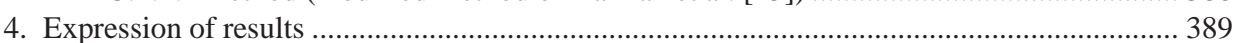

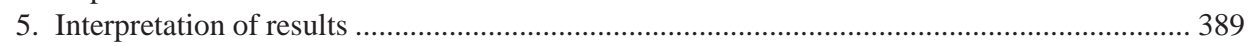

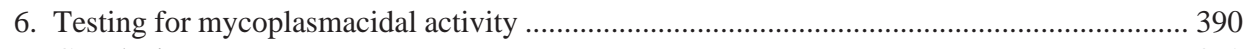

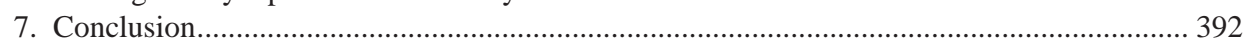




\section{INTRODUCTION}

Minimal inhibitory concentration (MIC) data on veterinary mycoplasma species have been generated by numerous researchers who have employed tests using various liquid or solid media $[1,4-6,10,12,13,15-17$, 19-22, 25-30, 32, 37-39, 42-44, 47, 48, $50,51]$. There has been little standardisation of procedures, making it difficult to compare MIC results from laboratory to laboratory [47].

Although guidelines for in vitro susceptibility testing criteria and quality control parameters for veterinary antimicrobial agents have recently been approved for veterinary bacteria [46], these do not include mycoplasmas (mollicutes) which are both slow growing, highly fastidious and do not produce the turbidity in broth nor sufficient growth on agar necessary for conventional antibacterial testing.

At the 1996 biennial meeting of the International Organisation for Mycoplasmology (IOM) International Research Programme on Comparative Mycoplasmology (IRPCM), the Board recommended that standard protocols be drawn up for veterinary MIC assays.

In mycoplasmology the MIC is defined as the lowest concentration of antimicrobial that will inhibit visible growth or metabolism of a mycoplasma species after its optimal incubation period in vitro. Despite reservations about their clinical relevance, MICs are still generally considered to be the reference point for comparison and evaluation of other sensitivity tests and indeed the efficacy of all antimicrobials is described in terms of MICs. The minimum mycoplasmacidal concentration (MMC) is defined as the lowest concentration of antimicrobial that prevents growth after subculture onto or into antibiotic-free media (in practice, approximately a $99.99 \%$ kill).

The wide variation in nutritional requirements and cultural conditions of veterinary mycoplasmas and the preference of certain species for agar rather than broth medium, has tended to hamper the development of a universal veterinary mycoplasmal MIC assay. This has been compounded by the need and preference for different formulations of mycoplasma media by workers in the poultry, swine, cattle, other farm industries and those dealing with companion (pet) animals. These and other problems in relation to the susceptibility testing of mollicutes in general have been highlighted recently in "Molecular and Diagnostic Procedures in Mycoplasmology Vol. II" [3, 23].

Recently attempts have been made to standardise and compare some veterinary MIC assay methods [4, 10, 42, 47]. The aim of this report is to discuss the factors which may influence veterinary MIC testing and to recommend basic procedures for carrying out such tests in the hope that consistent results can be achieved between laboratories in the future.

\section{GENERAL TECHNICAL CONSIDERATIONS}

\subsection{Media}

A standard medium for all veterinary mycoplasma MIC tests cannot currently be recommended because of the diversity of nutritional requirements of different mycoplasma species. In general, mycoplasma broth or agar giving the optimal growth of specific mycoplasmas or ureaplasmas should be employed in MIC tests. Suboptimal media giving poor growth may result in falsely low MIC values.

If penicillin or other $\beta$-lactam antibiotics (e.g. ampicillin), which are inactive against mycoplasmas because of their cell-wall deficiency, are incorporated to inhibit bacterial contamination, it should be borne in mind that they may interact with the compound under evaluation and that antagonism or even synergism might occur. It is therefore wise to establish if these phenomena occur with new antimicrobial agents and 
$\beta$-lactams before carrying out MICs using these bacterial inhibitors. However, penicillin G (1 $\left.000 \mathrm{IU} \cdot \mathrm{mL}^{-1}\right)$, ampicillin $\left(1000 \mu \mathrm{g} \cdot \mathrm{mL}^{-1}\right)$ or amoxycillin (1 $\left.000 \mu \mathrm{g} \cdot \mathrm{mL}^{-1}\right)$ with thallium acetate $\left(500 \mu \mathrm{g} \cdot \mathrm{mL}^{-1}\right)$, included in the culture medium have been found not to influence the MICs of erythromycin, spiramycin, streptomycin, tetracycline, tiamulin or tylosin against certain avian mycoplasmas [47]. Thallium acetate is inhibitory to ureaplasmas and should be excluded from tests involving these microorganisms.

Many different formulations of mycoplasma and ureaplasma media have been described for the culture of veterinary mycoplasmas. Some of these media, cited in "Methods in Mycoplasmology Vol. 1" $[9,36]$ are listed in Tables I and II. Other media have been used by various workers [1, $4,6,7,12,17,20,21,26,37,47,49,51]$.

Most veterinary mycoplasmas can be grown in liquid or on solid media and can therefore be used in MIC tests employing either type of medium. An exception to this is the turkey pathogen, $M$. meleagridis, par- ticularly fresh field isolates, which may be reluctant to grow or cause colour changes in liquid medium. MIC tests involving this mycoplasma species should therefore be carried out on solid media, at least until a suitable liquid medium has been developed.

Examples of media which have been used successfully by some investigators to carry out MIC assays against mycoplasmas from various animal host species, are shown in Table III.

Mycoplasmas develop only faint or no turbidity in broth cultures; consequently alternative methods are used to measure mycoplasmal growth. These include incorporation of substrates such as glucose, arginine or urea which are either fermented or hydrolysed by the mycoplasmas causing the medium to become acid or alkaline. These $\mathrm{pH}$ changes are usually detected by incorporating the $\mathrm{pH}$ indicator phenol red, into the mycoplasma broth, a colour change denoting mycoplasmal growth. Some mycoplasmas (e.g. M. iowae) metabolize both glucose and arginine and either substrate can be used to detect growth,

Table I. Liquid media used in the isolation and cultivation of veterinary mycoplasmas.

\begin{tabular}{|c|c|}
\hline Medium & Mycoplasmas cultured \\
\hline B & $\begin{array}{l}\text { Modified Hayflick - supports the growth of the } \\
\text { majority of mycoplasmas and acholeplasmas. }\end{array}$ \\
\hline $\mathrm{N}$ & $\begin{array}{l}\text { Modified Hayflick - superior to medium B for } \\
\text { M. anatis, M. bovigenitalium, M. edwardii, } \\
\text { M. felis, M. maculosum, M. meleagridis, } \\
\text { M. spumans, M. verecundum. }\end{array}$ \\
\hline F (Frey) & $\begin{array}{l}\text { Supports the growth of } M \text {. synoviae and other } \\
\text { avian mycoplasmas. }\end{array}$ \\
\hline A26 & $\begin{array}{l}\text { Supports the growth of } M \text {. hyopneumoniae and } \\
M \text {. flocculare and other porcine mycoplasmas. }\end{array}$ \\
\hline FF (Friis) & $\begin{array}{l}\text { Supports the growth of } M \text {. hyopneumoniae, } \\
M \text {. flocculare and other porcine mycoplasmas. }\end{array}$ \\
\hline GS & $\begin{array}{l}\text { Supports the growth of } M \text {. dispar and other bovine } \\
\text { mycoplasmas. }\end{array}$ \\
\hline SP4 & $\begin{array}{l}\text { For fastidious mycoplasmas including } M \text {. dispar, } \\
\text { M. synoviae, } M \text {. fastidiosum, M. feliminutum, } \\
\text { M. alvi and } M \text {. sualvi. }\end{array}$ \\
\hline
\end{tabular}

These media can be solidified by the addition of agar or agarose (for details refer to Methods in Mycoplasmology, Vol. $1[9])$ 
Table II. Media used in the isolation and cultivation of veterinary ureaplasmas.

\section{Liquid Media}

Urease colour change

broth 10C

(Shepard and Lunceford) [36]

Urease colour change broth

(Howard et al.) U4 [18]

Urea colour change test broth

(Taylor-Robinson et al.) [41]

\section{Solid Media}

Differential agar medium A8 (Shepard and Combs) [36]

Standard agar medium A5K

(Shepard and Lunceford) [36]

Standard agar medium (Taylor-Robinson et al.) [41]

Standard agar medium

(Howard et al.) [18]
Recommended for primary isolation and cultivation of ureaplasmas from animals.

Developed for bovine ureaplasmas.

Successfully used for the cultivation of ureaplasmas from primates.

Successfully used for the isolation and cultivation of ureaplasmas from animals.

Recommended for the isolation and culture of animal ureaplasmas.

Developed for the isolation and culture of bovine ureaplasmas.

For details refer to Methods in Mycoplasmology,Vol. 1 [36].

Table III. Examples of media which have been used by various researchers to carry out MIC tests against mycoplasma species from various animal hosts.

\begin{tabular}{|c|c|c|c|c|c|}
\hline \multirow[b]{2}{*}{ Medium } & \multicolumn{5}{|c|}{ Animal hosts } \\
\hline & Poultry & Pigs & Cattle & Sheep/Goats & Rodents \\
\hline \multicolumn{6}{|l|}{ Mycoplasmas } \\
\hline F (Frey) & {$[22]$} & & & & \multirow{9}{*}[13]{} \\
\hline Power and Jordan's & {$[4,20,21]$} & & & & \\
\hline FF (Friis) & [5] & {$[5,10,15,42,48]$} & {$[5,10,43]$} & & \\
\hline GS & & & [37] & & \\
\hline Edward [7] & & & [43] & & \\
\hline Hayflick & [5] & [5] & [10] & & \\
\hline B & & & [37] & [37] & \\
\hline $\begin{array}{l}\text { Mycoplasma enrichment } \\
\text { broth (Whithear) }\end{array}$ & [47] & & & & \\
\hline $\mathrm{ME}^{\mathrm{a}}$ & [16] & {$[16,17]$} & {$[16]$} & {$[16]$} & \\
\hline \multicolumn{6}{|l|}{ Ureaplasmas } \\
\hline N/HU (Friis) & & & [43] & & \\
\hline U9B & [37] & [37] & [37] & [37] & \\
\hline
\end{tabular}

Bracketed figures under host species: publications in which media were used.

${ }^{a} \mathrm{ME}$ (Mycoplasma Experience Ltd) medium is a commercially available medium suitable for growing highly fastideous mycoplasmas. 
however, others, e.g. M. bovis and $M$. agalactiae, which neither ferment glucose nor hydrolyse arginine, have recently been found to metabolize pyruvate, producing a permanent acid colour change [16]. For these mycoplasmas it is recommended that pyruvate be added to glucose-containing media for MIC tests. The use of tetrazolium reduction to facilitate colour changes with $M$. bovis has been reported but the colour changes tend to disappear after 1 to 2 days [43].

\subsection{Identification of mycoplasmas/ureaplasmas}

Ideally the species identification of mycoplasmas and ureaplasmas should be established before, or concurrently with, the testing of strains for susceptibility to antimicrobial agents. This involves the isolation and purification of strains to ensure that pure cultures are used in MIC tests. The large number of mycoplasma species inhabiting the respiratory and urogenital tracts of farm and domesticated animals and birds, many with similar colonial morphology, may make cloning obligatory. If this were not done, MIC test results would be on mixed cultures which would be misleading. If cloning is necessary then it is advisable to select several different clones and to carry out MIC tests on a mixture of these, to avoid selecting a minority resistant or sensitive sub-population. Cultures obtained from infection sites which are normally sterile, i.e. the joints, may be pure and in such instances broth cultures or agar blocks containing several colonies ( $\geq 5$ colonies) can be used to prepare inocula for MIC tests. The purity of such cultures should also be checked in parallel.

\subsection{Standardisation of inocula for MIC tests}

It is important that mycoplasma inocula for MIC tests are carefully standardized.
The accepted number of organisms used for tests carried out in liquid and on solid media is $10^{3}$ to $10^{5}$ colour changing units (ccu) per $\mathrm{mL}$ or colony forming units (cfu) per plate. Use of inocula falling outside this range may result in higher or lower MIC values, (higher for $>10^{5} \mathrm{ccu} / \mathrm{cfu}$ and lower for $<10^{3} \mathrm{ccu} / \mathrm{cfu}$ ) (Tab. IV, Hannan, unpublished data). The growth phase of the mycoplasmas seems to be less important. Whithear et al. [47] obtained identical MIC results with actively growing and frozen cultures of $M$. synoviae. Mycoplasma cultures of M. bovis, M. gallisepticum or M. hyopneumoniae in the lag phase, such as those obtained from freshly thawed cultures from $-70{ }^{\circ} \mathrm{C}$ diluted and used directly, or after $1-2 \mathrm{~h}$ incubation in broth at $36 \pm 1{ }^{\circ} \mathrm{C}$, and cultures in the logarithmic growth phase have, in our laboratory, given very similar results (Tab. V, Hannan unpublished data). However such comparisons have not been made with other mycoplasma species or ureaplasmas. Until it is established that such a correlation exists with other mollicutes, logarithmic phase cultures should be used routinely for MIC testing. It has been recommended also that mycoplasmas in the logarithmic phase of growth be used for initial surveys with new antibiotics [23].

An ATP-dependent luminometry method has also been reported recently for determining MICs of species that are highly fastidious or have long generation times and for agents with a short half life [3, 34]. Early logarithmic phase cultures are recommended for this method.

\subsection{Antimicrobial agents}

Ideally, antimicrobials should be obtained in powder form from the manufacturer accompanied by a statement of potency in relation to base ("as is" or anhydrous, in $\mu \mathrm{g}$ per mg) or as tablets, with details of optimum storage conditions, expiry date and solubility. Some compounds are available 


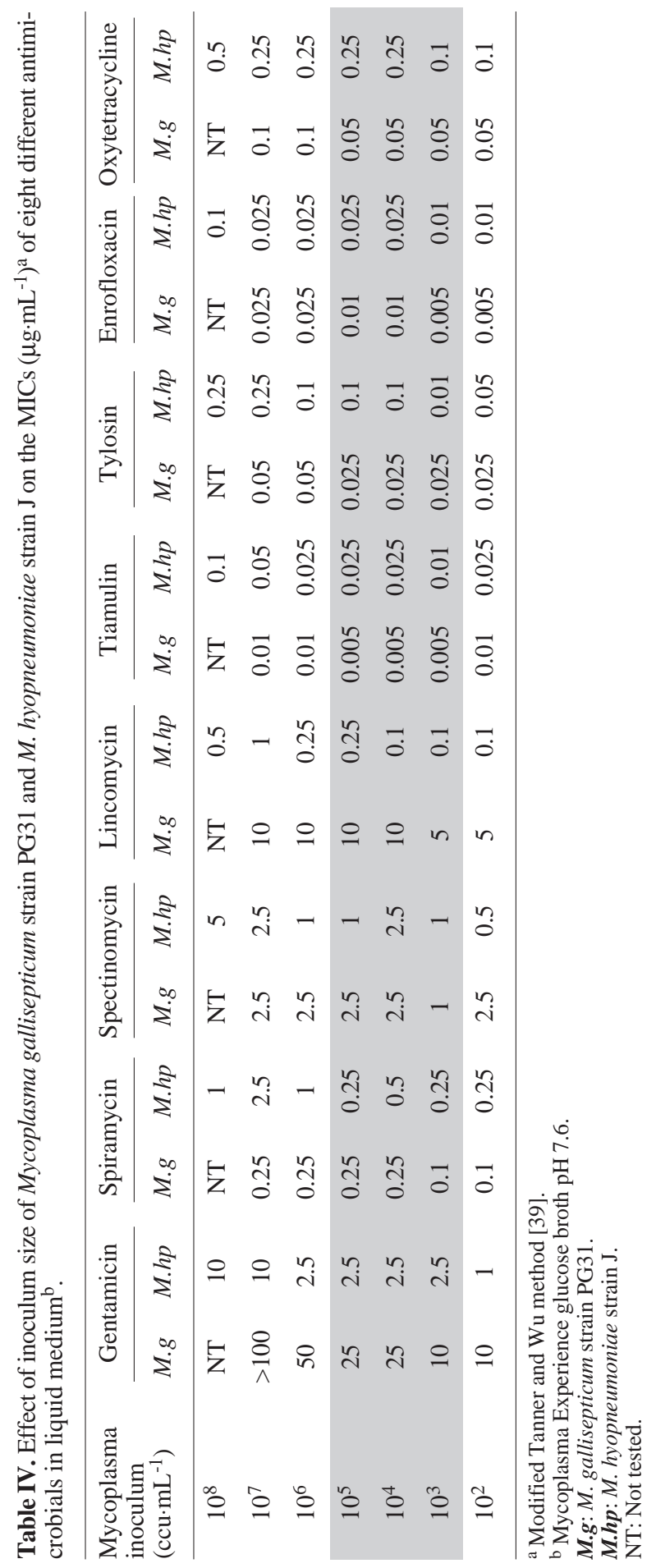


Table V. Effect of growth phase of Mycoplasma gallisepticum, Mycoplasma bovis and Mycoplasma hyopneumoniae on the MICs $\left(\mu \mathrm{g} \cdot \mathrm{mL}^{-1}\right)^{\mathrm{a}}$ of eight different antimicrobials in liquid medium ${ }^{\mathrm{b}}$.

\begin{tabular}{|c|c|c|c|c|c|c|c|c|c|}
\hline \multirow{3}{*}{$\begin{array}{l}\text { Antimicrobial } \\
\text { agent }\end{array}$} & \multicolumn{9}{|c|}{ Incubation time } \\
\hline & \multicolumn{3}{|c|}{$\begin{array}{l}\text { Freshly thawed } \\
\left(-70{ }^{\circ} \mathrm{C}\right) \\
0 \mathrm{~h} \\
\text { (lag phase) }\end{array}$} & \multicolumn{3}{|c|}{$\begin{array}{l}\text { Freshly thawed } \\
\quad\left(-70{ }^{\circ} \mathrm{C}\right) \\
+2 \mathrm{~h} \text { at } 36{ }^{\circ} \mathrm{C} \\
\text { (lag phase) }\end{array}$} & \multicolumn{3}{|c|}{$\begin{array}{l}\text { Freshly thawed } \\
\quad\left(-70{ }^{\circ} \mathrm{C}\right) \\
+48 \mathrm{~h} \text { at } 36^{\circ} \mathrm{C} \\
(\log \text { phase) }\end{array}$} \\
\hline & $\begin{array}{c}M . g \\
(P G 31)\end{array}$ & $\begin{array}{l}\text { M. bovis } \\
\text { (Donetta) }\end{array}$ & $\begin{array}{c}M . h p \\
(J)\end{array}$ & $\begin{array}{c}M . g \\
(P G 31)\end{array}$ & $\begin{array}{l}\text { M. bovis } \\
\text { (Donetta) }\end{array}$ & $\begin{array}{l}\text { M.hp } \\
(J)\end{array}$ & $\begin{array}{c}M . g \\
(P G 31)\end{array}$ & $\begin{array}{l}\text { M.bovis } \\
\text { (Donetta) }\end{array}$ & $\begin{array}{c}\text { M.hp } \\
\quad(J)\end{array}$ \\
\hline Gentamicin & 10 & 5 & 2.5 & 25 & 25 & 2.5 & 25 & 10 & 2.5 \\
\hline Spiramycin & 0.025 & 0.25 & 1 & 0.1 & 0.5 & 1 & 0.1 & 0.5 & 0.5 \\
\hline Spectinomycin & $>1$ & $>1$ & 1 & $>1$ & $>1$ & $>1$ & $>1$ & $>1$ & $>1$ \\
\hline Lincomycin & 0.5 & 0.25 & 0.25 & 1 & 0.25 & 0.5 & 1 & 0.5 & 0.25 \\
\hline Tiamulin & 0.005 & 0.05 & 0.05 & 0.005 & 0.05 & 0.05 & 0.01 & 0.05 & 0.025 \\
\hline Tylosin & 0.025 & 0.05 & 0.25 & 0.025 & 0.1 & 0.1 & 0.025 & 0.1 & 0.25 \\
\hline Enrofloxacin & 0.01 & 0.05 & 0.025 & 0.01 & 0.1 & 0.025 & 0.01 & 0.1 & NR \\
\hline Oxytetracycline & 0.1 & 0.1 & 0.25 & 0.05 & 0.1 & 0.5 & 0.1 & 0.1 & 0.25 \\
\hline
\end{tabular}

a Modified Tanner and Wu method [39].

${ }^{\mathrm{b}}$ Mycoplasma Experience (ME) glucose broth $\mathrm{pH} 7.6$ for M. gallisepticum and M. hyopneumoniae strains and ME glucose broth plus pyruvate $\mathrm{pH} 7.6$ for $M$. bovis.

Inoculum sizes: M. gallisepticum (PG31) $10^{5} \mathrm{ccu} \cdot \mathrm{mL}^{-1} ;$ M. bovis (Donetta) $10^{4}-10^{5} \mathrm{ccu} \cdot \mathrm{mL}^{-1} ;$ M. hyopneumoniae (J) $10^{4} \mathrm{ccu} \cdot \mathrm{mL}^{-1}$

NR: No result.

commercially and possible sources of supply in the UK include: Mast Diagnostics Ltd. Bootle, Merseyside; Unipath Ltd (oxoid), Basingstoke, Hampshire; Sigma Chemical Company, Poole, Dorset. It is essential that antimicrobials are within their expiry date and that they are stored according to the manufacturer's instructions.

\subsubsection{Storage}

Most antimicrobial powders can be stored at $+4{ }^{\circ} \mathrm{C}$ in the dark (quinolones, rifampicin and chloramphenicol are light sensitive), over a drying agent such as silica gel. However, some compounds are best stored at a temperature of $-20{ }^{\circ} \mathrm{C}$ or below (e.g. netilmicin). Before use they should be allowed to come to room temperature before they are opened (to avoid condensation of water). Aliquots of stock solutions, at concentrations in excess of $1000 \mathrm{mg} \cdot \mathrm{L}^{-1}$, can often be stored at $-60{ }^{\circ} \mathrm{C}$ for several months [8], but it must be remembered that a stock solution frozen and then thawed should be used immediately and then discarded (repeated freezing and thawing of solutions is not acceptable because of loss of potency). Table VI gives a summary of information on storage, solubility and stability for many commonly used compounds.

It is preferable to use fresh stock antibiotic solutions, however some antimicrobial solutions can be stored at $+4{ }^{\circ} \mathrm{C}$, frozen at $-20{ }^{\circ} \mathrm{C}$ or $-70{ }^{\circ} \mathrm{C}$, for limited periods until required for use, without loss of potency. The tetracyclines do not fall into this category as they tend to precipitate on thawing and should always be tested fresh. It is important to check the stability of specific compounds at $-20{ }^{\circ} \mathrm{C}$ before testing. The half-lives of antimicrobial compounds under test conditions may be important when testing slow-growing mycoplasmas and can be obtained from the manufacturer or a recent chemical index. For use in MIC tests, fresh or freshly thawed, antimicrobial solutions 
Table VI. Preparation and storage of antibiotic solutions $\left(1000 \mu \mathrm{g} \cdot \mathrm{mL}^{-1}\right)^{\mathrm{a}}$.

\begin{tabular}{|c|c|c|c|c|c|}
\hline \multirow[t]{2}{*}{ Antimicrobial } & \multirow[t]{2}{*}{ Diluent } & \multicolumn{3}{|c|}{ Storage of Solution } & \multirow[t]{2}{*}{ Storage of powder } \\
\hline & & $+4{ }^{\circ} \mathrm{C}$ & $-20^{\circ} \mathrm{C}$ & $-70^{\circ} \mathrm{C}$ & \\
\hline $\begin{array}{l}\text { Chloramphenicol } \\
\text { (chloromycetin) }\end{array}$ & $\begin{array}{l}\text { alcohol }^{\mathrm{b}} \text { and } \\
\text { water }\end{array}$ & & & & $4{ }^{\circ} \mathrm{C}$; protect from light \\
\hline $\begin{array}{l}\text { Ciprofloxacin } \\
\text { (hydrochloride } \\
\text { monohydrate) }\end{array}$ & water & 2 weeks & 3 months & 3 months & $\begin{array}{c}\text { below } 25^{\circ} \mathrm{C} \text { for } 3 \text { years; } \\
\text { protect from light }\end{array}$ \\
\hline $\begin{array}{l}\text { Clindamycin } \\
\text { (hydrochloride) }\end{array}$ & water & 1 day & unsuitable & & room temperature \\
\hline Erythromycin & $\begin{array}{l}\text { alcohol }{ }^{\mathrm{b}} \text { and } \\
\text { water }\end{array}$ & 1 week & & & $\begin{array}{c}+5^{\circ} \mathrm{C} \text { stable for } 3 \text { years; } \\
\text { protect from moisture } \\
\text { and light }\end{array}$ \\
\hline Fusidic acid & water or alcohol & & & & $25^{\circ} \mathrm{C}$ \\
\hline $\begin{array}{l}\text { Gentamicin } \\
\text { (sulphate) }\end{array}$ & water & 6 months & NR & NR & $\begin{array}{c}\text { unopened vials } 3 \text { years } \\
\text { at RT }\end{array}$ \\
\hline Metronidazole & water & & & & $25^{\circ} \mathrm{C}$; protect from light \\
\hline Netilmicin (sulphate) & water & 6 months & 6 months & 6 months & protect from light \\
\hline Rifampicin & $\begin{array}{l}\text { absolute } \\
\text { alcohol }^{\mathrm{b}} \\
\text { and water }\end{array}$ & 1 month & 1 month & & $+4{ }^{\circ} \mathrm{C}$; protect from light \\
\hline $\begin{array}{l}\text { Spectinomycin } \\
\text { (hydrochloride) }\end{array}$ & water & & & & \\
\hline $\begin{array}{l}\text { Sulphamethoxazole } \\
\text { (free acid) }\end{array}$ & $\begin{array}{l}0.1 \mathrm{~N} \mathrm{NaOH}^{\mathrm{b}} \\
\text { and water }\end{array}$ & 1 month & 6 months & 2 years & $5-25^{\circ} \mathrm{C}$; protect from light \\
\hline Tetracycline $^{c}$ & water & & NR & NR & unopened vials 2 years at RT \\
\hline Tobramycin & water & 1 week & 3 months & & $+5^{\circ} \mathrm{C}$; protect from moisture \\
\hline $\begin{array}{l}\text { Trimethoprim } \\
\text { (lactate) }\end{array}$ & $\begin{array}{l}\text { lactic acid }{ }^{\mathrm{b}} \\
\text { and water }\end{array}$ & 1 month & 6 months & 2 years & $5-25^{\circ} \mathrm{C}$; protect from light \\
\hline
\end{tabular}

NR: not recommended.

RT: room temperature.

a Data extracted from "a guide to sensitivity testing". Report of the working party of Antibiotic Sensitivity Testing of the British Society for Antimicrobial Chemotherapy [31].

${ }^{\mathrm{b}}$ Enough to dissolve the antimicrobial powder.

${ }^{\mathrm{c}}$ Formation of a precipitate on freezing.

${ }^{\mathrm{d}}$ Injectable not appropriate. 
are diluted in mycoplasma broth or agar to give the final required concentrations in MIC tests.

\subsubsection{Preparation of antimicrobial solutions for MIC testing}

Compounds can be tested directly as the formulation obtained (e.g. enrofloxacin hydrochloride), or in terms of the active base (e.g. enrofloxacin). Since different salts may differ considerably in their molecular weights, their active base contents will vary, weight for weight, and slightly different MIC values are likely to be obtained for different formulations. To avoid this, and to obtain consistent results between laboratories, antimicrobials should be tested in terms of their active base component. This is achieved by taking both the manufacturers stated purity and the salt content of the compound into account. The compound is then diluted allowing only for the base content. This is accomplished by applying a correction factor, calculated from the given purity of the compound, its molecular weight and the molecular weight of the active base. For example, if the stated purity of enrofloxacin hydrochloride is $80 \%$ and the molecular weights for enrofloxacin $\mathrm{HCl}$ and enrofloxacin base are 395.9 and 359.4 respectively, the correction factor is calculated as follows:

$\frac{359.4 \text { (MW enrofloxacin base) }}{395.9(\text { MW enrofloxacin } \mathrm{HCl})} \times \frac{80}{100}$ (purity) $=0.726$

This figure is then applied to the amount of enrofloxacin $\mathrm{HCl}$ weighed to obtain the weight of enrofloxacin base present, e.g.

$5 \mathrm{mg}($ enrofloxacin $\mathrm{HCl}) \times 0.726=$ $3.63 \mathrm{mg}$ enrofloxacin base.

In this example, to obtain a convenient final stock solution containing $1000 \mu \mathrm{g} \cdot \mathrm{mL}^{-1}$ enrofloxacin base, $5 \mathrm{mg}$ of enrofloxacin $\mathrm{HCl}$ would be dissolved in $3.63 \mathrm{~mL}$ (consisting of approximately $10 \%$ solvent and $90 \%$ sterile deionized water). Solutions can be ster- ilized by membrane filtration $(0.2 \mu \mathrm{m}$ pore size) before MIC testing, however the suitability of the filters should be checked with the manufacturers as some antimicrobials can adsorb to the membranes, Durapore 0.22 $\mu \mathrm{m}$ pore size TP cartridge (Hydrophilic Membrane) filters (Cat. No. CVGL 75501Millipore, Bedford, MA, USA) have been found to be suitable for filtering difloxacin. This filtration process can be omitted if all solutions, the compounds themselves and the apparatus used to carry out the tests are sterile, particularly if an antibacterial $\beta$-lactam such as ampicillin, is present in the culture medium.

Many commercial preparations of antimicrobials are water-soluble, but others, particularly those in the research stage, may require organic solvents, acids or alkalis to effect complete solubilization [31]. In general the compounds can be dissolved in a small volume (about one tenth the final volume) of the solvent and then made up to volume with deionized water. Agitation by vortexing, ultrasonic disintegration using a microprobe to disperse large particles, or mild warming may be required to obtain complete solutions.

Organic solvents which have been used include ethyl alcohol (EtOH), methyl alcohol $(\mathrm{MeOH})$, dimethyl formamide (DMF) and dimethyl sulphoxide (DMSO), and can be used for many classes of antimicrobial agent. Acids such as $0.1 \mathrm{~N}$ hydrochloric acid or acetic acid can also be used for certain agents. $0.1 \mathrm{~N}$ sodium hydroxide is recommended for initially dissolving many of the water-insoluble quinolone antimicrobials. Salts of these latter agents are generally water-soluble. Following complete solubilization under acidic or alkaline conditions, it is often necessary to adjust the $\mathrm{pH}$ of the compound solutions to approximately $\mathrm{pH} 7.0$ to avoid non-specific colour changes occurring in the higher drug concentrations in MIC tests.

To ensure that solvents are not inhibitory to the mycoplasmas it is important to include 
controls in MIC tests consisting of the solvent alone in mycoplasma broth at the same concentration as that used in the antimicrobial dilutions tested.

Where possible, antimicrobials should be tested at the correct $\mathrm{pH}$ for optimal in vitro activity, although this is governed by the ability of the mycoplasmas to grow well at that particular $\mathrm{pH}$. MIC determinations based on colour changes in the medium due to $\mathrm{pH}$ shifts should not be affected if the correct end-point controls are included in the assay. It is debatable whether the in vitro $\mathrm{pH}$ is pertinent to the in vivo situation since the $\mathrm{pH}$ at different infection sites and within cells, varies considerably. Macrolides such as erythromycin and its newer analogues are more potent under alkaline conditions $[2,11]$. A lesser, though significant, effect of $\mathrm{pH}$ on the testing of tetracyclines has also been reported [24]. Robertson et al. found that serum had no apparent binding effect on tetracycline, erythromycin or rosaramicin, but the expected decrease in macrolide activity against the human species Ureaplasma urealyticum at $\mathrm{pH} 6.0$ was clearly evident [35]. This acidity, however, does reflect the level in the genital tract where antimicrobial activity is expressed. It may be necessary to adjust media to neutral $\mathrm{pH}$, when dealing with mycoplasma or ureaplasma species isolated from other sites, although this may result in poorer growth of the microorganism.

\subsubsection{Antimicrobial dilution ranges}

Antibiotic dilution ranges are usually obtained by carrying out doubling dilutions, the highest final drug concentration frequently being $64 \mu \mathrm{g} \cdot \mathrm{mL}^{-1}$. In liquid MIC tests in microdilution plates, the drug concentrations are usually prepared at double the final concentration (e.g. $128 \mu \mathrm{g} \cdot \mathrm{mL}^{-1}$ ) to allow for dilution with an equal volume of drug-free medium containing the mycoplasma inoculum. For MIC tests on solid medium the drug is incorporated into the agar plates at the final concentrations required, allowance being made for the larger volume of medium, e.g. if the final volume of medium per plate is $20 \mathrm{~mL}$ then $1 \mathrm{~mL}$ of drug solution at 20 times its final required concentration is incorporated in $19 \mathrm{~mL}$ of molten mycoplasma agar $\left(50 \pm 1{ }^{\circ} \mathrm{C}\right)$ immediately before pouring the plates. In practice, $1 \mathrm{~mL}$ of the antimicrobial solution is pipetted into a sterile plastic universal container; the molten agar is then added, mixed by gentle inversion, and the plate poured immediately, to reduce the chance of possible heat inactivation of the compound under test. All plates should be of a uniform thickness. Drug dilutions can either be prepared in tubes or bottles using pipettes or automatic pipetters with sterile filter tips and then transferred to microdilution plate wells or molten agar, or they can be prepared directly in microtitre trays using various types of manual or automated microdilutors.

To minimize the chances of excessive drug "carry over" and other possible dilution errors, compounds may be diluted in tubes using a combination of doubling dilutions and dilutions in 10-fold series. This procedure involves carrying out a series of 10fold dilutions of the compound concerned in sterile tubes or bottles; two doubling dilutions from each drug concentration produced by the 10 -fold dilution procedure are then carried out. If the highest final required concentration is $100 \mu \mathrm{g} \cdot \mathrm{mL}^{-1}$, then the range of dilutions covered is similar to those produced by the conventional doubling dilution method starting at $64 \mu \mathrm{g} \cdot \mathrm{mL}^{-1}$.

\subsection{Validation of equipment}

All equipment including chemical balances, automatic pipetters, multi-channel micro-pipetters and inoculators should be routinely checked for accuracy of weighing or delivery. Incubators should be checked regularly for accuracy of temperature. 
Table VII. Comparative MICs of five classes of antimicrobial agents against reference strains of avian, porcine and bovine mycoplasma species obtained using liquid and solid media by various investigators.

\begin{tabular}{|c|c|c|c|c|}
\hline \multirow[b]{2}{*}{$\begin{array}{l}\text { Organism } \\
\text { (type strain) } \\
\text { and antimicrobial }\end{array}$} & \multicolumn{4}{|c|}{$\operatorname{MIC}\left(\mu \mathrm{g} \cdot \mathrm{mL}^{-1}\right)$} \\
\hline & $\begin{array}{c}\text { Liquid } \\
\text { medium (Mod. } \\
\text { Tanner and } \\
\text { Wu) 1992 } \\
\text { [39] }\end{array}$ & $\begin{array}{l}\text { Solid } \\
\text { medium } \\
\text { (Hannan } \\
\text { et al.) } 1989 \\
\text { [15] }\end{array}$ & $\begin{array}{l}\text { Liquid medium } \\
\text { (other workers) }\end{array}$ & $\begin{array}{l}\text { Solid medium } \\
\text { (other workers) }\end{array}$ \\
\hline $\begin{array}{l}\text { M. gallisepticum PG31 } \\
\text { Enrofloxacin } \\
\text { Flumequine } \\
\text { Tiamulin } \\
\text { Tylosin } \\
\text { Oxytetracycline }\end{array}$ & $\begin{array}{c}0.01 \\
0.5 \\
0.0025 \\
0.01 \\
0.1\end{array}$ & $\begin{array}{l}0.025^{\mathrm{a}, \mathrm{c}} \\
\geq 10^{\mathrm{a}} \\
0.025^{\mathrm{a}} \\
0.5^{\mathrm{a}} \\
0.5^{\mathrm{a}}\end{array}$ & $\begin{array}{c}0.007[28] \\
0.016-0.045^{\mathrm{a}}[4,28] \\
0.5-1^{\mathrm{a}}[4,39]\end{array}$ & $\begin{array}{c}0.1[21] \\
0.01-0.1[21] \\
0.1-1[21]\end{array}$ \\
\hline $\begin{array}{l}\text { M. synoviae WVU } 1853 \\
\text { Enrofloxacin } \\
\text { Flumequine } \\
\text { Tiamulin } \\
\text { Tylosin } \\
\text { Oxytetracycline }\end{array}$ & $\begin{array}{c}0.5 \\
10 \\
0.1 \\
0.025 \\
0.1\end{array}$ & $\begin{array}{l}0.025^{\mathrm{c}} \\
\geq 10 \\
0.25 \\
0.025 \\
0.1\end{array}$ & & $\begin{array}{l}0.1-1[21] \\
0.1-1[11] \\
0.1[11]\end{array}$ \\
\hline $\begin{array}{l}\text { M. iowae } 695 \\
\text { Enrofloxacin } \\
\text { Flumequine } \\
\text { Tiamulin } \\
\text { Tylosin } \\
\text { Oxytetracycline }\end{array}$ & $\begin{array}{l}0.005 \\
5 \\
0.005 \\
0.5 \\
0.25\end{array}$ & $\begin{array}{l}0.025^{\mathrm{b}, \mathrm{c}} \\
>10^{\mathrm{b}} \\
0.025^{\mathrm{b}} \\
2.5^{\mathrm{b}} \\
0.5^{\mathrm{b}}\end{array}$ & $\begin{array}{l}0.05[28] \\
0.05[28]\end{array}$ & \\
\hline $\begin{array}{l}\text { M. meleagridis } \mathbf{1 7 5 2 9} \\
\text { Enrofloxacin } \\
\text { Flumequine } \\
\text { Tiamulin } \\
\text { Tylosin } \\
\text { Oxytetracycline }\end{array}$ & $\begin{array}{l}0.1^{\mathrm{d}} \\
10^{\mathrm{d}} \\
0.1^{\mathrm{d}} \\
0.1^{\mathrm{d}} \\
1^{\mathrm{d}}\end{array}$ & $\begin{array}{l}0.1^{\mathrm{c}} \\
\geq 10 \\
0.25 \\
0.1 \\
5\end{array}$ & & $\begin{array}{c}1[21] \\
0.25-1[21,28] \\
0.1-1[21,28]\end{array}$ \\
\hline $\begin{array}{l}\text { M. hyopneumoniae J } \\
\text { Enrofloxacin } \\
\text { Flumequine } \\
\text { Tiamulin } \\
\text { Tylosin } \\
\text { Oxytetracycline }\end{array}$ & $\begin{array}{l}0.05 \\
0.5 \\
0.025 \\
0.025 \\
0.25\end{array}$ & $\begin{array}{l}0.01^{\mathrm{c}} \\
2.5 \\
0.05 \\
0.01 \\
0.25\end{array}$ & $\begin{array}{l}\leq 0.03[42] \\
\leq 0.03[19,42] \\
\leq 0.03[19,42] \\
0.12[19,42,48]\end{array}$ & \\
\hline $\begin{array}{l}\text { M. hyosynoviae } \mathbf{S 1 6} \\
\text { Enrofloxacin } \\
\text { Flumequine } \\
\text { Tiamulin } \\
\text { Tylosin } \\
\text { Oxytetracycline }\end{array}$ & $\begin{array}{l}0.25 \\
25 \\
0.025 \\
0.05 \\
0.5\end{array}$ & $\begin{array}{l}0.5^{c} \\
\geq 10 \\
0.025 \\
0.025 \\
5\end{array}$ & $\begin{array}{c}0.25[10] \\
0.0025[10] \\
0.025-0.09[10,51]\end{array}$ & \\
\hline $\begin{array}{l}\text { M. hyorhinis BTS-7 } \\
\text { Enrofloxacin } \\
\text { Flumequine } \\
\text { Tiamulin } \\
\text { Tylosin } \\
\text { Oxytetracycline }\end{array}$ & $\begin{array}{c}0.5 \\
5 \\
0.05 \\
0.5 \\
0.05\end{array}$ & $\begin{array}{l}0.25^{\mathrm{c}} \\
\geq 10 \\
0.25 \\
0.25 \\
0.25\end{array}$ & $\begin{array}{c}0.8-2[26,42] \\
\leq 0.03-0.1[26,42] \\
0.06-0.4[26,42] \\
0.12-0.4[26,42,48]\end{array}$ & $\begin{array}{l}0.8[26] \\
0.4[26] \\
0.8[26] \\
0.4[26]\end{array}$ \\
\hline $\begin{array}{l}\text { M. bovis Donetta } \\
\text { Enrofloxacin } \\
\text { Flumequine } \\
\text { Tiamulin } \\
\text { Tylosin } \\
\text { Oxytetracycline }\end{array}$ & $\begin{array}{l}0.25 \\
10 \\
0.05 \\
0.05 \\
0.1\end{array}$ & $\begin{array}{l}1^{\mathrm{c}} \\
\geq 10 \\
0.1 \\
0.5 \\
0.5\end{array}$ & $\begin{array}{c}1-2[43] \\
\leq 0.015[43] \\
0.125[43] \\
\quad 4[43]\end{array}$ & \\
\hline
\end{tabular}

a Strain $\mathrm{S6}$.

b Strain B11.

c Results for ciprofloxacin, chemically very similar to its analogue enrofloxacin.

d Unpublished data. 


\subsection{Incubation conditions}

Since most mycoplasmas and ureaplasmas grow well between $35^{\circ} \mathrm{C}$ and $37^{\circ} \mathrm{C}$, a temperature of $36 \pm 1{ }^{\circ} \mathrm{C}$ is recommended for liquid and solid MIC assays, unless it is established that optimal growth occurs at a temperature outside this range.

In liquid microtitre MIC assays, it is essential that each well is securely sealed to prevent exchange of gases between wells which may result in false colour changes and erroneous MIC end-points. The seal on unused wells should be punctured to avoid lifting of the sealant by air expansion within the wells during incubation. If plates are incubated in a humidified cabinet at an appropriate incubation temperature and in a suitable gaseous environment, then all wells should be vented to allow escape of gaseous products of metabolism of the substrates in inoculated wells.

In solid medium assays, plates should be incubated in an atmosphere (e.g. aerobic, $95 \% \mathrm{~N}_{2}+5 \% \mathrm{CO}_{2}$, or anaerobic) suitable for growing the mycoplasma species and strains under examination. Plates should be suitably dried prior to inoculation to allow absorption of the mycoplasma inoculum and to prevent cross-contamination of the mycoplasma species or strains. This is particularly important when automated multipoint inoculator heads delivering many different mycoplasma species or strains are used. It is important that the plates do not dry excessively during incubation as this can inhibit mycoplasmal growth and lead to erroneous MIC values. Drying can be avoided by including paper towelling moistened with sterile water containing an antifungal agent, such as sodium propionate, in the container containing the MIC plates.

Incubation times of different mycoplasma species and strains vary considerably. In liquid MIC tests incubation times are controlled by the time it takes for particular mycoplasmas or ureaplasmas to cause colour changes equivalent to pre-set $\mathrm{pH}$ controls. However, in agar MIC tests the incubation times should be sufficient to allow adequate growth of the slowest growing mycoplasma species under test.

\section{MYCOPLASMA MIC METHODS}

Both liquid and solid MIC methods have been used in determining MICs against veterinary mycoplasma species. Examples of these methods are the liquid method described by Tanner and Wu [39], originally designed to test strains of $M$. gallisepticum and the solid agar method described by Hannan et al. [15]. Both of these methods are also applicable to testing mycoplasmas of human origin and have been used to test a variety of different mycoplasma species from various animal hosts. The results obtained by the two methods are in many instances, in close agreement (Tab. VII). This is in accordance with results obtained for the human species Ureaplasma urealyticum by Waites et al. [45], where $\mathrm{MIC}_{50} \mathrm{~S}$ and $\mathrm{MIC}_{90} \mathrm{~s}$ obtained in broth were only four-fold lower than those on agar. It is therefore recommended that the Tanner and $\mathrm{Wu}$ method be adopted for mycoplasma species which grow well in broth and Hannan et al.'s modified method for those which grow either in broth or on agar. The liquid method is simple to carry out and is convenient for testing small numbers, while the agar system is ideal for evaluating large numbers of mycoplasma strains or species on the same agar plate, if a multipoint inoculation system (Denley Ltd, Billingshurst, Sussex, UK) is employed. The latter system would be the method of choice for testing strains of $M$. meleagridis. The liquid method could also be applied to tubes if small numbers of strains were to be tested. Further information on the MIC testing of mollicutes has been published recently by Bébéar and Robertson [3]. 


\subsection{Liquid MIC method}

\subsubsection{Preparation of stock mycoplasma cultures}

Following primary isolation and identification, the mycoplasmas are grown at $36 \pm$ $1{ }^{\circ} \mathrm{C}$ in $10 \mathrm{~mL}$ broth medium containing the appropriate substrate (glucose, arginine, pyruvate or urea) and $\mathrm{pH}$ indicator (phenol red) until a colour change occurs (pink to orange-yellow for glucose and pyruvate fermenters, and orange-yellow to pink or red for arginine and urea catabolizers). Sterile glycerol (cryoprotectant) is then added (optional) to each culture to a final concentration of approximately 5\% v/v and the cultures are divided into $5 \times 1 \mathrm{~mL}$ aliquots in sterile containers and stored at $-70{ }^{\circ} \mathrm{C}$.

\subsubsection{Preparation of mycoplasma inocula for MIC testing}

1. Thaw a $1-\mathrm{mL}$ vial of frozen inoculum $\left(-70{ }^{\circ} \mathrm{C}\right)$ and add $4 \mathrm{~mL}$ of the appropriate medium set at $\mathrm{pH} 7.6$ for glucose or pyruvate metabolizers, $\mathrm{pH} 6.8$ for arginine or pH 6.0 to 6.5 for urea catabolizers.

2. Incubate the diluted culture at $36 \pm 1{ }^{\circ} \mathrm{C}$ until a definite acid or alkaline reaction is observed.

3. Record the time taken (in hours) for this reaction to occur.

4. Carry out a viable count immediately. (To compare MICs obtained with lag phase cultures and those of logarithmic phase cultures, the thawed cultures can be used either directly or after incubation for $2 \mathrm{~h}$ at $36^{\circ} \mathrm{C}$ prior to inoculating the antibiotic dilutions. In the first instance steps 1 to 3 above for logarithmic phase cultures are omitted. One millilitre of the thawed culture is diluted in $9 \mathrm{~mL}$ of broth, and then vortexed for $5 \mathrm{~s}$ prior to carrying out a viable count. In the second instance, steps 1 to 3 for logarithmic cultures are also omitted. One millilitre of the thawed culture is diluted in $9 \mathrm{~mL}$ of growth medium, which after vortexing for $5 \mathrm{~s}$ is incubated for $2 \mathrm{~h}$ at $36{ }^{\circ} \mathrm{C}$. Thereafter viable counting procedures and MIC testing with the various inocula are identical).

\subsubsection{Viable counting method for liquid MIC assays}

1. Add $1 \mathrm{~mL}$ of mycoplasma culture to $9 \mathrm{~mL}$ of sterile diluent (mycoplasma broth or broth base) and vortex (Autovortex mixer SA1 (or equivalent) Stuart Scientific Company Ltd, Redhill, Surrey, UK) the suspension for $5 \mathrm{~s}$ to reduce possible clumping of the mycoplasmas.

2. Prepare 10-fold dilutions of the vortexed suspension from $10^{-2}-10^{-9}$ in $0.9 \mathrm{~mL}$ volumes.

3. Add $0.1 \mathrm{~mL}$ of sterile mycoplasma broth at the appropriate $\mathrm{pH}$ to 8 consecutive wells in a horizontal row of a round bottomed microdilution plate (NUNC A/S Roskilda, Denmark), wells 1-8.

4. Add $0.2 \mathrm{~mL}$ of sterile mycoplasma broth to well number 12 (sterility control).

5. Transfer $0.1 \mathrm{~mL}$ of each mycoplasma dilution to the $0.1 \mathrm{~mL}$ volumes of broth in a microdilution plate beginning at well number 8 and finishing at well number 1 .

6. Seal the microdilution plate using an adhesive sealing film (Falcon, Beckton Dickenson and Co., Oxnard, CA, USA) and roller, first puncturing the seal on all unused wells to prevent lifting of the film due to air expansion during incubation. Complete the sealing by rubbing the surface of the film around each well with a smooth object such as the back of a spoon (manufactured from plastic or horn).

7. Incubate the plate at $36 \pm 1{ }^{\circ} \mathrm{C}$ until colour changes are complete.

8. Record the result; the lowest dilution to show a colour change (approximately 0.2 $\mathrm{pH}$ unit) denotes the reciprocal of the number of colour changing units (ccu) 
in $0.1 \mathrm{~mL}$ of undiluted mycoplasma culture. For example, if colour changes are recorded to a dilution of $10^{-6}$, then there are $10^{6} \mathrm{ccu}$ in $0.1 \mathrm{~mL}$ of the undiluted culture or $10^{7} \mathrm{ccu} \cdot \mathrm{mL}^{-1}$.

\subsubsection{Preparation of inocula for liquid MIC assays}

1. Repeat the incubation procedure described in 3.1 .2 ("Preparation of mycoplasma inocula for MIC testing") duplicating exactly the period of incubation.

2. Dilute the culture in mycoplasma broth to give between $10^{3} \mathrm{ccu}$ and $10^{5} \mathrm{ccu}$ per $\mathrm{mL}$.

\subsubsection{Modified MIC assay method of Tanner and Wu method [39]}

1. Transfer $0.1 \mathrm{~mL}$ of each compound dilution to separate consecutive wells running horizontally on a microdilution plate (e.g. wells 1 through to 9).

2. To well number 10 add $0.2 \mathrm{~mL}$ of sterile mycoplasma broth at the appropriate $\mathrm{pH}$ (e.g. $\mathrm{pH}$ 7.6, for fermentative species, $\mathrm{pH} 6.8$ for arginine catabolizers or $\mathrm{pH}$ 6.0-6.5 for ureaplasmas), as a sterility control.

3. To well number 11 , add $0.2 \mathrm{~mL}$ of sterile mycoplasma broth adjusted to the required end-point ( $\mathrm{pH} 6.8$ for fermentative species, $\mathrm{pH} 7.6$ for arginine catabolizers or $\mathrm{pH} 7.0-7.5$ for ureaplasmas end point control).

4. To row number 12 add $0.1 \mathrm{~mL}$ of sterile mycoplasma broth at the appropriate $\mathrm{pH}$.

5. In a separate row add $0.1 \mathrm{~mL}$ of antibiotic-free mycoplasma broth at the appropriate $\mathrm{pH}$ containing the antibiotic solvent at the same concentration used to dissolve the antimicrobial agent (solvent control).
6. Add $0.1 \mathrm{~mL}$ of mycoplasma inoculum to each well containing the antibiotic dilutions (wells 1 to 9), to the growth control well (well 12) and to the solvent control well.

Each MIC test should include a standard reference mycoplasma (e.g. the type strain of each species under investigation) with known susceptibilities against a range of antimicrobials, to confirm the validity of results and a standard antimicrobial agent e.g. (tiamulin) with known potencies against different species of veterinary mycoplasma.

The viable count of each mycoplasma challenge inoculum must be tested simultaneously with the MIC test to confirm the inoculum challenge as being between $10^{3}$ and $10^{5} \mathrm{ccu}$ per $\mathrm{mL}$.

7. Seal the microdilution plate with adhesive film as described above under "Viable counting method for liquid MIC assays" and incubate at $36 \pm 1{ }^{\circ} \mathrm{C}$ until the colour in the growth control well first matches that of the end-point control. To achieve this, plates must be examined at frequent intervals e.g. early morning, noon, late afternoon.

8. Record the initial MICs; the lowest antibiotic concentration to show no change in colour when the colour of the growth control well matches that of the $\mathrm{pH}$ end-point control. By definition this is the MIC value, however if plates are reincubated the end-point in liquid assay frequently shifts. For this reason a second reading is often taken and is referred to as the final MIC. Final readings can be recorded 7 days later or 14 days later for slow growing mycoplasma species such as M. hyopneumoniae, to determine the permanency of the initial MIC and is the lowest drug concentration in which no colour change occurs.

9. Continue incubating the plates until colour changes are complete in the wells containing the inoculum challenge control viable count. 
Where MIC end-points are not achieved, or if the mycoplasma challenge falls outside the range $10^{3} \mathrm{ccu} \cdot \mathrm{mL}^{-1}$ to $10^{5} \mathrm{ccu} \cdot \mathrm{mL}^{-1}$, tests must be repeated.

When the initial MIC and final MIC are the same or very similar, this may be indicative of a compound possessing mycoplasmacidal activity. However, this should be confirmed with MMC tests designed to demonstrate this property, such as diluting the contents of wells showing no colour change into antibiotic free mycoplasmal broth, followed by incubation, to check the absence of viable mycoplasmas. The dilution needs to be sufficient to prevent carry over of the inhibitory effect of each dilution of antibiotic and should be in the order of 1:25 to 1:50. Alternatively, mycoplasmal killing curve experiments may be carried out.

\subsection{Solid agar MIC method}

\subsubsection{Viable counting method for solid MIC assays}

1. Repeat the incubation procedure described in Section 3.1.2 ("Preparation of mycoplasma inocula for MIC testing") duplicating exactly the period of incubation.

2. Repeat steps 1 and 2 in Section 3.1.3 for liquid assay viable counts.

3. Transfer $2 \mu \mathrm{L}$ of each mycoplasma dilution (in triplicate or more for greater accuracy) to the surface of freshly prepared and dried mycoplasma agar plates using a micropipetter and filter tip.

4. When the droplets of each suspension have been absorbed into the agar, incubate the plate at $36 \pm 1{ }^{\circ} \mathrm{C}$ under the appropriate atmospheric conditions (e.g. aerobic, $95 \% \mathrm{~N}_{2}+5 \% \mathrm{CO}_{2}$ or anaerobic) in sealed containers containing moistened paper towelling.

5. Incubate the seeded plates until the mycoplasma colonies are well developed on the plates inoculated with the lower dilutions of the mycoplasma suspension.

6. Select plates with a moderate growth of well separated colonies for counting. Avoid plates with low numbers of colonies.

7. Using a plate microscope or inverted microscope, count the number of colonies produced by each $2 \mu \mathrm{L}$ droplet. The number of cfu per $2 \mu \mathrm{L}$ of inoculum is the mean count from the three droplets (or more if additional droplets are counted).

\section{Example:}

If the colony counts from an individual $2 \mu \mathrm{L}$ droplet for a $10^{-5}$ dilution of inoculum are $30 \mathrm{cfu}, 40 \mathrm{cfu}$ and $35 \mathrm{cfu}$ then the mean count would be 35 cfu per $2 \mu \mathrm{L}$. Therefore, to prepare inocula containing between $10^{3}$ and $10^{5} \mathrm{cfu}$ per $2 \mu \mathrm{L}$ for MIC testing, the concentrated culture should be diluted $10^{-3}$ to give $3.5 \times 10^{3} \mathrm{cfu}$ per $2 \mu \mathrm{L}$, which is within the recommended number for MIC testing.

\subsubsection{Method (modified method of Hannan et al. [15])}

1. Prepare agar plates containing a range of antimicrobial concentrations in $9 \mathrm{~cm}$ plastic petri dishes as described in Section 2.4.3. Also, prepare control drugfree plates.

2. Dry the plates.

3. Inoculate each plate with $2 \mu \mathrm{L}$ containing $10^{3}-10^{5} \mathrm{cfu}$, of the mycoplasma culture to be tested using either micro-pipetters with filter tips, if only a small number of strains are to be tested, or a multi-point inoculator if larger numbers of strains are to be tested simultaneously. Whichever method is used, growth control plates (up to four to allow for possible bacterial or fungal contamination) without antibiotics must be included in each test. 
4. Include the following controls:

(a) Reference strain (the type strain of each mycoplasma species being tested).

(b) Plates incorporating a reference antimicrobial (e.g. tiamulin).

(c) Plates incorporating the solvents used for each antimicrobial at the same concentration as that used in the highest concentration of the drugcontaining plates.

(d) A challenge inoculum growth control.

5. When the inoculum droplets have been absorbed, incubate the plates at $36 \pm 1{ }^{\circ} \mathrm{C}$ either aerobically or in an atmosphere of $95 \% \mathrm{~N}_{2}+5 \% \mathrm{CO}_{2}$ or anaerobically, if growth of the species is dependant on these latter conditions). Incubation should be maintained in moist conditions, in sealed plastic bags or gas jars, for a period sufficient to allow the slowest growing mycoplasma species to form clearly visible colonies, e.g. 7 days or longer if species such as M. hyopneumoniae or M. meleagridis are being investigated.

6. Record MICs by comparing the amount of mycoplasmal growth on each plate with that on the antibiotic-free growth control plate using a plate microscope or inverted microscope. The end-point (MIC) is the lowest concentration of antimicrobial to cause $\geq 50 \%$ inhibition of growth (e.g. reduction in density of growth and size of the colonies) compared with that on the control plate. A $50 \%$ end-point is taken to eliminate plates in which antibiotics show a "tailing effect" (very small numbers of mycoplasmas persisting beyond, what appears to be, the end-point).

Very often readings can be carried out macroscopically, but end-points should always be checked microscopically.

\section{EXPRESSION OF RESULTS}

Whether using liquid or solid MIC assays, MICs are expressed either in $\mu \mathrm{g} \cdot \mathrm{mL}^{-1}$ or $\mathrm{mg} \cdot \mathrm{L}^{-1}$. When only small numbers of strains $(n \leq 10)$ are tested at the same time, it is usual to quote only the range of MICs recorded (e.g. MIC range $=0.1 \mu \mathrm{g} \cdot \mathrm{mL}^{-1}$ to $10 \mu \mathrm{g} \cdot \mathrm{mL}^{-1}$ ) to give an overall impression of the variance between strains. However, in larger studies, it is important to highlight the percentages of strains susceptible to particular concentrations of antimicrobials. This is accomplished by quoting the concentrations of compounds to which $50 \%$ or $90 \%$ of the strains are susceptible $\left(\mathrm{MIC}_{50}\right.$ or $\left.\mathrm{MIC}_{90}\right)$. In comparing in vitro efficacies of marketed or research compounds the geometric mean MIC has been used by some workers. Examples of these calculations are shown in Table VIII.

\section{INTERPRETATION OF RESULTS}

The designations "sensitive", "resistant" or "intermediate" (moderately sensitive) are common to almost all methods of clinical laboratory testing, and are distinguished by the use of in vitro breakpoint antibiotic concentrations. Sensitive implies that the infection is likely to respond. Intermediate implies that an intermediate or indeterminate response is likely, except perhaps in special, defined circumstances, such as when high doses can be used, or the antibiotic is concentrated at the site of infection. Breakpoints are determined by attempting to take important pharmacological and microbiological factors into account, including serum binding, and are used routinely in bacterial infections. These factors have not yet been determined for most veterinary mycoplasmas in the various host species in which they may cause disease, although some investigators have attempted to establish breakpoints for some compounds against certain mycoplasmal pathogens $[16,22,42$, 43] (Tab. IX). This is due to the limited 
Table VIII. Expression of results in MIC tests: ranges, $\mathrm{MIC}_{50} \mathrm{~s}, \mathrm{MIC}_{90} \mathrm{~s}$ and geometric mean MICs.

\begin{tabular}{lc}
\hline Mycoplasma strain No. & MIC $\left(\mu \mathrm{g} \cdot \mathrm{mL}^{-1}\right)$ \\
\hline 1 & $0.01^{\mathrm{a}, \mathrm{b}}$ \\
2 & $0.005^{\mathrm{a}, \mathrm{b}}$ \\
3 & $0.1^{\mathrm{b}}$ \\
4 & $0.01^{\mathrm{a}, \mathrm{b}}$ \\
5 & $0.0025^{\mathrm{a}, \mathrm{b}}$ \\
6 & $0.05^{\mathrm{a}, \mathrm{b}}$ \\
7 & $0.1^{\mathrm{b}}$ \\
8 & $0.25^{\mathrm{b}}$ \\
9 & $0.5^{\mathrm{b}}$ \\
10 & 1 \\
\hline MIC range $_{\text {MIC }}$ & $0.0025-1$ \\
MIC $_{90}$ & $0.05^{2}$ \\
Geometric mean & 0.5 \\
\hline
\end{tabular}

${ }^{\text {a }}$ Values used to determine the $\mathrm{MIC}_{50}$ (e.g. $50 \%$ of the strains are susceptible to $\left.\leq 0.05 \mu \mathrm{g} \cdot \mathrm{mL}^{-1}\right)$.

${ }^{b}$ Values used to determine the MIC $_{90}$ (e.g. $90 \%$ of the strains are susceptible to $\leq 0.5 \mu \mathrm{g} \cdot \mathrm{mL}^{-1}$ ).

To calculate the geometric mean MIC the logarithm of the MIC values for each strain are summed, divided by the number of strains tested and then antilogged.

pharmacological data currently available on many antimicrobials in different animal species.

Until such information becomes available, a standardized assessment of sensitive, intermediate and resistant strains is difficult. It is therefore likely that in determining the antimicrobial susceptibilities of veterinary mycoplasmas, some variance in these designations will occur between laboratories.

\section{TESTING FOR MYCOPLASMACIDAL ACTIVITY}

Various tests have been used to determine the mycoplasmacidal activity of antimicrobials. These include:

1. Mycoplasmacidal activity determined by antibiotic dilution.
2. Mycoplasmacidal activity determined by filtration.

3. Mycoplasmacidal activity determined by subculture onto agar.

4. Mycoplasma killing curves.

Methods 1 and 2 have been designed specifically to remove the antibiotic from the surviving mycoplasmas in MIC tests and thus give a true indication of the mycoplasmacidal activity of antimicrobial agents. These methods have been described fully by Taylor-Robinson [40].

Method 3 consists of subculturing all of the wells in liquid MIC tests using a 96-pin replicater/inoculator (Intek Services Ltd, Horley, Surrey, UK) onto mycoplasmal agar at the same time as recording the initial MICs and then incubating the plates to determine the lowest concentration of compound to inhibit mycoplasmal growth, the MMC. The results of this type of test are frequently very similar to the final MICs in MIC tests. However, the test does not remove the antibiotics from the mycoplasmas and relies on the very small amount of culture transferred on to replicater pins $(2 \mu \mathrm{L})$ being diluted by diffusion into the agar gel. It is therefore possible that, in theory, a mycoplasmastatic effect might still be in operation in high concentrations of antibiotic. This method has been described by Hannan [14].

Method 4, mycoplasmacidal killing curves, have been reviewed recently by Roberts [33] and are a measure of the mycoplasmacidal activity of the antibiotic being tested, thus providing a dynamic picture of antimicrobial action and interaction over time, based on serial colony counts. However, the repetitive colony counts that are required are tedious to perform and limit the number of antimicrobial concentrations that can be tested with any isolate. This type of test has been used to determine the mycoplasmacidal activities of certain quinolones and various other antibiotics against $M$. hyopneumoniae by Hannan et al. [15]. 


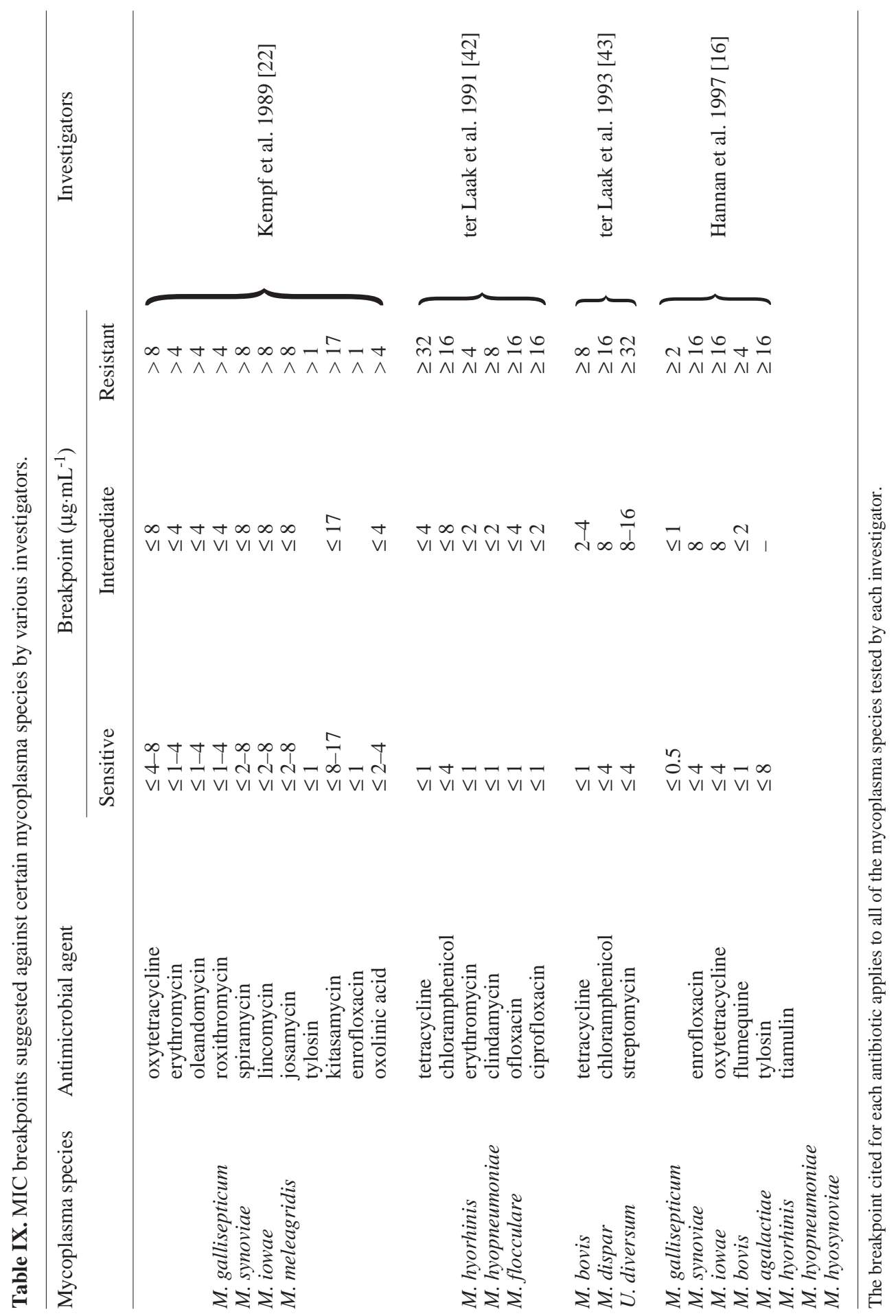




\section{CONCLUSION}

In view of the wide variation in nutritional requirements, cultural conditions and growth characteristics of veterinary mycoplasmas, it is not surprising that difficulties have been encountered in obtaining consistent MIC results from different laboratories. There are many factors which can influence the results of MIC tests involving veterinary mycoplasma species, including the composition and $\mathrm{pH}$ of the culture medium, the incubation conditions and the preference of certain mycoplasma species for agar rather than broth media. Whether using a liquid or solid MIC assay system, it is essential that, to avoid obtaining falsely low MIC results, optimal media for growing specific mycoplasma species are used, that cultures are pure and that mycoplasma inocula are carefully standardised. The recommended viable counts for inocula are $10^{3}$ to $10^{5} \mathrm{ccu} \cdot \mathrm{mL}^{-1}$ for liquid assays and $10^{3}$ to $10^{5} \mathrm{cfu}$ per plate for the agar dilution method. The growth phase of the organisms seems to be less important as lag phase cultures of $M$. gallisepticum, M. synoviae, $M$. bovis and $M$. hyopneumoniae have been shown to give very similar results to cultures in the logarithmic growth phase in liquid assays.

Antimicrobials should be stored according to the manufacturers recommendations and MICs determined in terms of their active base component, particularly when comparing results between laboratories. In liquid and solid MIC assays it is important that tests are carefully controlled, with growth, sterility, $\mathrm{pH}$ end-point (in liquid assays) and compound solvent controls and that standard reference mycoplasmas with established antibiotic sensitivity patterns are included in each experiment. In liquid MIC assays the microdilution plates must be adequately sealed to prevent exchange of gases between wells which might result in false colour changes and erroneous MIC endpoints and that the reading of liquid or solid MIC tests are carefully standardised. These factors, coupled with a dearth of standardisation of MIC procedures between laboratories to date, have made it almost inevitable that significant differences in results would occur. This report should aid in rectifying this problem. Inter-laboratory studies employing standardised methods with a common range of antimicrobial agents against standard veterinary mycoplasma species and strains are now needed to determine whether consistent results can be achieved.

\section{ACKNOWLEDGEMENTS}

Prepared on behalf of the International Research Programme on Comparative Mycoplasmology (IRPCM) Chemotherapy Team of the International Organisation for Mycoplasmology (IOM). The author thanks the following members of the IOM IRPCM Chemotherapy working party and consultants for their contributions, comments, criticisms, help and suggestions in preparing the manuscript and for reviewing the final document: Dr H.J. Ball (Veterinary Sciences Division, Stormont, Belfast, Northern Ireland); Dr J.M. Bradbury (Dept. of Avian Pathology, University of Liverpool, Leahurst, Neston, South Wirral, UK); Dr N.F. Friis (Danish Veterinary Laboratory, Copenhagen, Denmark); Dr I. Kempf (Agence Française de Sécurité Sanitaire des Aliments (AFSSA), Ploufragan, France); Dr S. Kleven (Department of Avian Medicine, University of Georgia, Athens, Ga., USA); Dr S. Levisohn (Division of Poultry Diseases, Kimron Veterinary Institute, Bet Dagan, Israel); Dr R. Nicholas (Central Veterinary Laboratory, Addlestone, Surrey, UK); Prof. J.A. Robertson (Department of Medical Microbiology, Immunology, University of Alberta, Edmonton, AB T6G 2H7, Canada); Prof. L. Stipkovits (Veterinary Medical Research Institute, Budapest, Hungary); Dr K.B. Waites (Dept. of Pathology, University of Alabama, Birmingham, AL, USA); Dr J.M. Wilson (Glaxo Laboratories, Greenford, Middlesex, UK); Dr G.D. Windsor (Mycoplasma Experience Ltd, Reigate, Surrey, UK); Prof. K. Whithear (University of Melbourne, School of Veterinary Science, Werribee, Victoria, Australia). The author also thanks Mrs. S. 
Hayes and Mrs. E. Windsor for their parts in typing the manuscript.

\section{REFERENCES}

[1] Ball H.J., Craig-Reilly G.A., Bryson D.G., Antibiotic susceptibility of Mycoplasma bovis strains isolated in Northern Ireland, Irish Veterinary Journal 48 (1995) 316-318.

[2] Bébéar C., Antibiotic Sensitivity Testing, Introductory Remarks, in: Tully J.G., Razin S. (Eds.), Molecular and Diagnostic Procedures in Mycoplasmology, Vol. II, Diagnostic Procedures, Academic Press, London, 1996, pp.181-183.

[3] Bébéar C., Robertson J.A., Determination of Minimal Inhibitory Concentration, in: Tully J.G., Razin S. (Eds.), Molecular and Diagnostic procedures in Mycoplasmology, Vol. II, Diagnostic Procedures, Academic Press, London, 1996, pp.189-197.

[4] Bradbury J.M., Yavari C.A., Giles C.J., In vitro evaluation of various antimicrobials against Mycoplasma gallisepticum and Mycoplasma synoviae by the micro-broth method and comparison with a commerically-prepared test system, Avian Pathol. 23 (1994) 105-115.

[5] Cooper A.C., Fuller J.R., Fuller M.K., Whittlestone P., Wise D.R., In vitro activity of danofloxacin, tylosin and oxytetracycline against mycoplasmas of veterinary importance, Res. Vet. Sci. 54 (1993) 329-334.

[6] Devriese L.A., Haesebrouck F., Antibiotic susceptibility testing of Mycoplasma bovis using Tween 80 hydrolysis as an indicator of growth. Zentralbl. Veterinaermed. B 38 (1991) 781-783.

[7] Edward D.G. ff., A selective medium for pleuropneumonia-like organisms, J. Gen. Microbiol. 1 (1947) 238-243.

[8] Ericsson H.M., Sherris J.C., Antibiotic sensitivity testing, Report of an international collaborative study, Acta. Pathol. Microbiol. Scand, Suppl. Section B 217 (1971) 1-90.

[9] Freundt E.A., Culture media for classic Mycoplasmas, in: Razin S., Tully J.G. (Eds.), Methods in Mycoplasmology, Vol. 1, Mycoplasma Characterization, Academic Press, London, 1983, pp. 127-135.

[10] Friis N.F., Szancer J., Sensitivity of certain porcine and bovine mycoplasmas to antimicrobial agents in a liquid medium test compared to a disc assay, Acta. Vet. Scand. 35 (1994) 389-394.

[11] Garrod L.P., O'Grady F., Macrolides, in: Antibiotic and Chemotherapy, 3rd Ed. Churchill Livingstone, Edinburgh and London, 1972, pp.166181.

[12] Hamdy A.H., Blanchard C.J., In-vitro activity of lincomycin and spectinomycin against serotypes of avian mycoplasma, Appl. Microbiol. 20 (1970) 26-30.
[13] Hannan P.C.T., Sodium aurothiomalate, gold keratinate and various tetracyclines in mycoplasmainduced arthritis in rodents, J. Med. Microbiol. 10 (1977) 87-102.

[14] Hannan P.C.T., Antibiotic susceptibility of Mycoplasma fermentans strains from various sources and the development of resistance to aminoglycosides in vitro, J. Med. Microbiol. 42 (1995) 421-428.

[15] Hannan P.C.T., O’Hanlon P.J., Rogers N.H., In vitro evaluation of various quinolone antibacterial agents against veterinary mycoplasmas and porcine respiratory bacterial pathogens, Res. Vet. Sci. 46 (1989) 202-211.

[16] Hannan P.C.T., Windsor G.D., de Jong A., Schmeer N., Stegemann M., Comparative susceptibilities of various animal-pathogenic mycoplasmas to fluoroquinolones, Antimicrob. Agents Chemother. 41 (1997) 2037-2040.

[17] Hannan P.C.T., Windsor H.M., Ripley P.H., In vitro susceptibilities of recent field isolates of Mycoplasma hyopneumoniae and Mycoplasma hyosynoviae to valnemulin (Econor), tiamulin and enrofloxacin and the in vitro development of resistance to certain antimicrobial agents in Mycoplasma hyopneumoniae, Res. Vet. Sci. 63 (1997) 157-160.

[18] Howard C.J., Gourlay R.N., Collins J., Serological studies with bovine ureaplasmas (Tmycoplasmas), Int. J. Syst. Bacteriol. 28 (1978) 473-477.

[19] Inamoto T., Takahashi H., Yamamoto K., Nakai Y., Ogimoto K., Antibiotic susceptibility of Mycoplasma hyopneumoniae isolated from swine, J. Vet. Med. Sci. 56 (1994) 393-394.

[20] Jordan F.T.W., Knight D.L., The minimal inhibitory concentration of kitasamycin, tylosin and tiamulin for Mycoplasma gallisepticum and their protective effect on infected chicks, Avian Pathol. 13 (1984) 151-162.

[21] Jordan F.T.W., Gilbert S., Knight D.L., Yavari C.A., Effects of Baytril, Tylosin and Tiamulin on avian mycoplasmas, Avian Pathol. 18 (1989) 659-673.

[22] Kempf I., Ollivier C., L'Hospitalier R., Guittet M., Bennejean G., Concentrations minimales inhibitrices de 13 antibiotiques vis-à-vis de 21 souches de mycoplasmes de volailles, Le Point Vétérinaire 20 (1989) 935-940.

[23] Kenny G.E., Problems and opportunities in Susceptibility Testing of Mollicutes, in: Tully J.G., Razin S. (Eds.), Molecular and Diagnostic procedures in Mycoplasmology, Vol. II, Diagnostic Procedures, Academic Press, London, 1996, pp. 185-188.

[24] Kenny G.E., Cartwright F.D., Susceptibilities of Mycoplasma hominis, Mycoplasma pneumoniae and Ureaplasma urealyticum to new glycyclines in comparison with those to older tetracyclines, Antimicrob. Agents Chemother. 38 (1994) 26282632. 
[25] Kleven S.H., Anderson D.P., In vitro activity of various antibiotics against Mycoplasma synoviae, Avian Dis. 15 (1971) 551-557.

[26] Kobayashi H., Morozumi T., Munthali G., Mitani K., Ito N., Yamamoto K., Macrolide susceptibility of Mycoplasma hyorhinis isolated from piglets, Antimicrob. Agents. Chemother. 40 (1996) 10301032.

[27] Koh H-B, Kim G-N, Lee J-G., Minimum inhibitory concentrations of tiamulin and oxytetracycline in combination in field isolates of Mycoplasma hyopneumoniae, Proc. Int. Pig. Vet. Soc. 13th IPVS Congress, Bangkok, Thailand, June 26-30, 1994, p. 353.

[28] Levisohn S., Antibiotic sensitivity patterns in field isolates of Mycoplasma gallisepticum as a guide to chemotherapy, Isr. J. Med. Sci. 17 (1981) 661-666.

[29] Levisohn S., Berman E., Weisman Y., Effect of treatment of turkeys under field conditions with tylosin or enrofloxacin on frequency of isolation and sensitivity patterns of Mycoplasma meleagridis, Public Health Rev. 20 (1993) 183.

[30] Levisohn S., Gerchman I., Weisman Y., Antibiotic resistance in Mycoplasma iowae: Selective pressure by field treatment, IOM Letters Vol. 4. 11 th International Congress of the International Organisation for Mycoplasmology (IOM), Orlando, Florida, USA, July 14-19, 1996, p. 404405.

[31] Phillips I., Andrews J.M., Bridson E., Cooke E.M., Holt H.A., Spencer R.C., Wise R., Bint A.J., Brown D.F.J., Greenwood D., King A., Williams R.J., A guide to sensitivity testing, Report of the working party on Antibiotic Sensitivity Testing of the British Society for Antimicrobial Chemotherapy. J. Antimicrob. Chemother. Suppl. D 27 (1991) 1-50.

[32] Poumarat F., Martel J.L., Antibiosensibilité in vitro des souches françaises de Mycoplasma bovis, Ann. Rech. Vét. 20 (1979) 145-152.

[33] Roberts M.C., Antibiotic resistance, in: Maniloff J., McElhaney R.N., Finch L.R., Baseman J.B. (Eds.), Mycoplasmas: Molecular Biology and Pathogenesis, American Society for Microbiology, Washington D.C., 1992, pp. 513-523.

[34] Robertson J.A., Stemke G.W., Measurement of Mollicute Growth by ATP-Dependent Luminometry, in: Razin S., Tully J.G (Eds.), Molecular and Diagnostic Procedures in Mycoplasmology, Vol I., Molecular Characterization, Academic Press, London, 1995, pp. 65-71.

[35] Robertson J.A., Coppola J.E., Heisler O.R., Standardized Method for Determining Antimicrobial Susceptibility of Strains of Ureaplasma urealyticum and their response to Tetracycline, Erythromycin and Rosaramicin, Antimicrob. Agents Chemother. 20 (1981) 53-58.

[36] Shepard M.C. Culture media for Ureaplasmas, in: Razin S., Tully J.G. (Eds.), Methods in Mycoplasmology, Vol. 1, Mycoplasma Charac- terization, Academic Press, London, 1983, pp. 137-146.

[37] Stipkovits L., Varga Z., Laber G., Böchmann J., A comparison of the effect of tiamulin hydrogen fumarate and tylosin tartrate on mycoplasmas of ruminants and some animal ureaplasmas, Vet. Microbiol. 9 (1984) 147-153.

[38] Takahashi I., Yoshida T., Antimycoplasma activities of ofloxacin and commonly used antimicrobial agents on Mycoplasma gallisepticum, Jap. J. Antibiot. 42 (1989) 1166-1172.

[39] Tanner A.C., Wu C.C., Adaptation of the Sensititre broth microdilution technique to antimicrobial susceptibility testing of Mycoplasma gallisepticum, Avian Dis. 36 (1992) 714-717.

[40] Taylor-Robinson D., Cidal activity testing, in: Tully J.G., Razin S. (Eds.), Molecular and Diagnostic Procedures in Mycoplasmology, Vol. II, Diagnostic Procedures, Academic Press, London, 1996, pp. 199-204.

[41] Taylor-Robinson D., Martin-Bourgon C., Watanabe T., Addey J.P., Isolation of Tmycoplasmas from dogs and squirrel monkeys: Biological and Serological comparison with those isolated from man and cattle, J. Gen. Microbiol. 68 (1971) 97-107.

[42] Ter Laak E.A., Pijpers A., Noordergraaf J.H., Schoevers E.C., Verheijden J.H.M., Comparison of methods for in vitro testing of susceptibility of porcine mycoplasma species to antimicrobial agents, Antimicrob. Agents Chemother. 35 (1991) 228-233.

[43] Ter Laak E.A., Noordergraaf J.H., Verschure M.H.. Susceptibilities of Mycoplasma bovis, Mycoplasma dispar and Ureaplasma diversum strains to antimicrobial agents in vitro, Antimicrob. Agents Chemother. 37 (1993) 317-321.

[44] Wachowski Ch., Kirchhoff H., Studies of sensitivity of Mycoplasma bovis field strains to various antibiotics and chemotherapeutics, Berl. Muench. Tieraerztl. Wochenschr. 99 (1986) 41-44 (in German).

[45] Waites K.B., Figarola T.A., Schmid T., Crabb D.M., Duffy L.B., Simecka J.W., Comparison of agar versus broth dilution techniques for determining antibiotic susceptibilities of Urealasma urealyticum, Diagn. Microbiol. Infect. Dis. 14 (1991) 265-271.

[46] Watts J.L., Chengappa M.M, Cole J.R., Cooper J.M., Inzana T.J., Plaunt M.R., Shyrock T.R., Thornsberry C., Walker R.D., Wu C.C., Development of in vitro susceptibility testing criteria and quality control parameters for veterinary antimicrobial agents; Approved guideline, NCCLS document M37-A [ISBN 1-56238-3698], Vol. 19, No. 3, 1999.

[47] Whithear K.G., Bowtell D.D., Ghiocas E., Hughes K.L., Evaluation and use of a Micro-Broth Dilution Procedure for testing sensitivity of fermentative avian mycoplasmas to antibiotics, Avian Dis. 27 (1983) 937-949. 
[48] Williams P.P., In vitro susceptibility of Mycoplasma hyopneumoniae and Mycoplasma hyorhinis to fifty-one antimicrobial agents, Antimicrob. Agents Chemother. 14 (1978) 210213.

[49] Windsor G.D., Edward D.G. ff., Trigwell J.A., A solid medium for culture and identification of human T-mycoplasmas., J. Med. Microbiol. 8 (1975) 183-187.
[50] Yamamoto K., Koshimizu K., In vitro susceptibility of Mycoplasma hyopneumoniae to antibiotics, Proc. Int. Vet. Soc. 8th IPVS Congress, Ghent, Belgium, Aug. 27-31, 1984, p. 116.

[51] Zimmerman B.J., Ross R.F., Determination of sensitivity of Mycoplasma hyosynoviae to tylosin and selected antibacterial drugs by a microtitre technique, Can. J. Comp. Med. 39 (1975) 17-21. 